\title{
The Factors Affecting the Development of National Identity as South Korean in North Korean Refugees Living in South Korea
}

\author{
Shi-Eun $\mathrm{Yu}^{1}$, Jin-Sup Eom ${ }^{2}$ and Woo-Taek Jeon ${ }^{3,4} \bowtie$ \\ ${ }^{1}$ Department of International Health, Bloomberg School of Public Health, Johns Hopkins University, Baltimore, MD, USA \\ ${ }^{2}$ Department of Psychology, Chungbuk National University, Cheongju, Republic of Korea \\ ${ }^{3}$ Department of Psychiatry, College of Medicine, Yonsei University, Seoul, Republic of Korea \\ ${ }^{4}$ Department of Medical Education, College of Medicine, Yonsei University, Seoul, Republic of Korea
}

Objective This study aims to observe the factors that influence the development of national identity of North Korean refugees who have resettled in South Korea.

Methods The study population was comprised of 500 North Korean refugees who immigrated to South Korea in 2007. The variables measured national identity as South Korean, a scale for discrimination perceived during daily life, a social for supporting social network, a for childhood trauma experience, traumatic experiences in North Korea, and traumatic experiences during the escape process. Factor analysis was conducted on the result from the scale for national identity as South Korean which produced 4 factors including national consciousness, positive emotions, positive values, and negative values. Multiple regression was done to identify how variables such as demographic data, discrimination, social network, and past trauma had influenced each of 4 factors.

Results National identity was negatively related by traumatic experience during childhood, perceived discrimination, and positively influenced by social networks. Positive emotion was related negatively to education level in North Korea and perceived discrimination, but positively related to traumatic experiences in North Korea. Negative value was related positively age and perceived discrimination but negatively related to supporting social network.

Conclusion The results of this study suggests that promoting social networks, decreasing discrimination and healing past traumas were important factors for North Korean refugees in South Korea to facilitate a new national identity as a South Korean.

Psychiatry Investig 2012;9:209-216

Key Words North Korean Refugee, National Identity, Surrounding discrimination, Networking, Trauma experience.

\section{INTRODUCTION}

Throughout Korea's long history, Korean people have lived under a unified language and culture as "one ethnicity, one nation". During the period of 1950 to 1955 , the Cold War separated by the Americans and Soviets and established two governments in Korea according to ideology between the South Korea and North Korea. Since then, Korea has been divided into North Korea and South Korea. However, Il Sung Kim, who ruled North Korea for 50 years, died in 1994, the gov-

Received: October 26, 2011 Revised: March 6, 2012

Accepted: April 29, 2012 Available online: September 6, 2012

$\triangle$ Correspondence: Woo-Taek Jeon, MD

Department of Psychiatry, Department of Medical Education, Yonsei University College of Medicine, 50 Yonsei-ro, Seodaemun-gu, Seoul 120-752, Republic of Korea

Tel: +82-2-2228-2510, Fax: +82-2-364-5450, E-mail: wtjeon@yuhs.ac

(c) This is an Open Access article distributed under the terms of the Creative Commons Attribution Non-Commercial License (http://creativecommons.org/licenses/by$\mathrm{nc} / 3.0$ ) which permits unrestricted non-commercial use, distribution, and reproduction in any medium, provided the original work is properly cited. ernment of North Korea began to lose its stranglehold on its people. Since 1994, the number of North Korean refugees greatly increased because of poor conditions in North Korea, such as food shortages and economic difficulties. It was reported at the end of 2011 that the number of North Korean refugees was more than 23,000. ${ }^{1}$ The South Korea government has been actively supporting North Korean refugees to resettle through diverse economic support, such as residency support, education, employment, and financial assistance. ${ }^{2}$ However, many of the North Korean refugees residing in the South are facing a national identity crisis, whose suggested causes include discrimination, a lack of support system, and trauma. As the number of refugees keeps growing, the South Korean government has been under pressure to avoid controversy financially due to the difficulties in equally supporting the poor in South Korea and the North Korean refugees. Since, a more fundamental question has been raised with regards to North Korean refugees having a sense of identity and belonging in 
their new life in South Korea. National identity is defined as, "the manner or self-perception assumed by members of a nation to think and talk about the nationhood."3 National identity is important because people feel pride and affection, membership and loyalty, and a sense of superiority toward the nation to which they belong. It is also important because emotional immersion in one's nation influences their ethos and behavioral patterns. ${ }^{4-6}$

Past studies have shown many diverse factors that affect North Korean refugees' formation of national identity in South Korea. ${ }^{3,4}$ North Korean refugees' sense of identity is affected by socio-economic factors such as gender, age, and educational status. ${ }^{7.8}$ Therefore, this study will explore factors that have not been previously investigated, such as discriminatory experiences, social network, and traumatic experiences for North Koreans who relocate to life in South Korea.

Discrimination is reported to play an important role in making an individual's identity. ${ }^{9}$ Social identity may negatively affect an individual if society negatively stereotypes the group with which an individual identifies ${ }^{10}$; thus, the negative psychological effects of discrimination and social identity are likely to be highly interrelated in immigrants from negatively stereotyped groups. Despite this, relatively little is known about the effect discrimination plays on how young refugees adjust to their new lives, and how social identity influences their experiences of discrimination. ${ }^{9}$ According to Yoon, North Korean refugees who experience discrimination from South Koreans also feel isolated and consequently have difficulty developing a sense of belonging in the South Korean society. ${ }^{11}$ He also reported that in the process of settling down in South Korean, North Korean refugees develop a multi-faceted identity, including an identity both as a South Korean and a North Korean, as well as an identity as a same ethnic origin and as foreign migrant worker. ${ }^{11}$ According to the results of a study comparing the national identity of children who had migrated to Korea and that of South Korean children based on how much discrimination they had experienced, the migrant children have relatively weak national identity compared to the non-migrant children and also have lower social support and self-esteem. ${ }^{12}$ Moreover, the children who had migrated to South Korea were more prone to depression.

Social networks are also known as an important factor in the formation of national identity. Identity is not created or developed by an individual alone but achieved through mutual interactions with others. In other words, how often one interacts with another member of the society in a given situation is a crucial matter in the development and change in identity. ${ }^{13,14}$ Obtaining and maintaining one's identity is not simply a matter of preference or culture, but is related to how much resource an individual has that allows him/her to obtain his/her identity. Moreover, it has already been well documented that an individual's social network not only influences the physical health but also the psychological well-being. ${ }^{15}$ For North Korean refugees, societal support becomes an important resource for coping with their life and an important factor in predicting their psychological adaptation. ${ }^{16-18}$ Studies have shown that the identity of women who migrated to South Korea through international marriage are affected by the difficulties of learning Korean language and culture, human relationships and societal support. ${ }^{19}$ One previous study showed that social networks with family, friends, a sponsor, participation in community group, or emotional support group positively influences North Korean refugees' mental health. ${ }^{20}$

We also focused on external traumatic experiences that impact the formation of one's identity. There is evidence that an individual's sense of belonging to a specific community is related to one's personal traumatic experiences in the past. ${ }^{20}$ For refugees, trauma experienced is not a single-event, but tends to accumulate over time, so it may lead to an identity confusion. ${ }^{21}$ The study shows that childhood trauma affects interpersonal relationship, sense of belonging, identity, and discriminatory reactions in a negative way., ${ }^{922}$ Therefore, an assessment has to be made on the overall affect of trauma on North Korean refugees and how it relates to them establishing a sense of national identity as a South Korean. This study explored trauma of North Korean refugees by categorizing trauma experienced in North Korea before and after the age of 16 .

The object of this study is to explore the established national identity as a South Korean among North Koreans and then assess how socioeconomic characteristics, discriminatory experiences, social network, and trauma is related to their sense of national identity.

\section{METHODS}

\section{Sample and setting}

This study sample is based on the North Korean refugees, who immigrated into South Korea from January 1, 2007 to December, 2007. This study tried to maintain homogeneity among the study subjects by considering the fact that North Korean refugees may change in their sense of national identity depending on their settlement period. We selected our subjects from those who have settled in South Korea for a relatively short period of time but at least have settled for one year. This study was conducted in 2009, so we chose our subjects from those who had settled in South Korea in 2007.

In April 2009, 2,138 North Korean refugees who immigrated to South Korea in 2007 were contacted, however 1,447 subjects were unreachable. Of the remaining 691 people who were reachable, 107 subjects declined to participate in the stu- 
dy leaving 584 participants. All participants participated voluntarily. 500 subjects were willing to participate in a face-toface interview. IRB approval from Severance Hospital was received prior to the start of the survey.

\section{Instrument}

\section{The National Identity Scale}

To measure national identity of North Korean refugees, we used the national identity scale, which was modified from and composed with 29 questions. We adjusted and used Seong's Korean Social Identification Scale, ${ }^{23}$ which was based on Tajfel's social identity theory, ${ }^{24}$ Keum's Korean Cultural Identity Scale, ${ }^{25}$ Chung's Korean Sense of Community Scale, ${ }^{26}$ Kim's Korean Community Self-esteem Scale, ${ }^{27}$ and Chae's North Korean Culture Orientation and South Korean Cultural Orientation. ${ }^{7}$ The national identity scale includes 9 questions about their perception of membership to a country, 6 questions concerning their feelings about belonging to a country, and 14 questions about the value of belonging to a country.

Also, five North Korean refugees participated in a pilot study three times to determine the reading comprehension level of North Korean refugees.

The 29 items are rated on a 4-point response scale to see if they think and feel that they are South Korean: $1=$ complete disagreement, 2 =disagreement, $3=$ agreement, $4=$ complete agreement. The 29 items on the national identity study were extracted into 21 items and 4 factors through factor analysis.

In terms of awareness as a citizen, the Cronbach's alpha was 0.815 , which measures the internal consistency reliability. The Cronbach alpha score for positive emotion factor was 0.885 . The Cronbach's alpha for positive value factor was 0.767 and that of the negative value factor was 0.700 .

\section{Essed's Everyday Discrimination Scale}

The Korean version of Essed's everyday discrimination sc$\mathrm{ale}^{28}$ is composed of 9 questions concerning the discrimination that they repeatedly experience in their daily lives on a scale of 4 points (Cronbach's alpha $=0.88$ ).

\section{Social Network Scale}

To assess their social network, we asked the subjects about their mutual relationships with another North Korean refugees, which is defined as "personal network" by Wellman et al. ${ }^{29,30}$ We used the scale developed by Yeom. ${ }^{31}$ The content of the questions is composed of seven fields related to the information and help that North Korean refugees feel they need in their daily lives. The seven areas are as follows: companionship, emotional aid, information, services (such as child care or health care), money, information of education, and goods. We also counted the number of people who offered them support and information after completing the course at Hanawon ${ }^{a}$ and analyzed them in this study. The statistics used were made from numerating the total number of the participants.

\section{Scale for Childhood trauma experience}

We used 10 questions concerning the childhood trauma experience from the National Co-morbidity Survey, which is a section of the American Changing Lives. ${ }^{32}$ The questions examined 10 traumatic experiences in childhood, such as the death of parents, physical abuse by parents or family, psychological abuse, sexual abuse, abandoned by parents, parental divorce, parental drinking problems, psychological illness, chronic illness or disability, and suicide of a family member or friend. Participants answered the questions with either "yes" or "no". We summed all of the positively answered questions and used that as the score for childhood trauma experience.

\section{The Traumatic Experiences Scale for North Korean Refugees}

To measure more specific, difficult traumatic experiences by the North Korean refugees, we used the scale developed by Kang. ${ }^{33}$ This scale is composed of 25 questions about the traumatic experiences a subject had in North Korea and 19 questions about the traumatic experiences during his/her escape process. From the scale, we selected 17 questions about traumatic experiences a subject had in North Korea and 18 questions about traumatic experiences during his/her escape. All of the questions were yes-no questions. The content of the questions include life-threatening experiences due to cold or lack of food, shooting or being chased, extreme beating, time spent in concentration camps or jail, suspected of personal affairs, punished for political error, separation with family, serious illness, experiencing famine, witnessing public execution, torture, natural disaster, humiliation or rape, human trafficking, betrayal, arrest or deportation to North Korea, sudden death of family or friends, and loss of contact with family. The statistics separately sum the traumatic experiences in North Korea and the traumatic experiences during escape.

\section{Data analysis}

This study used SPSS 12.0 for data analysis and conducted a descriptive statistics for all variables. The factor analysis was done on the result of national identity scale identify the factor structure national identity. A multiple regression analysis

\footnotetext{
${ }^{a}$ Hanawon is a national institute at which North Korean refugees entering South Korea receive education on basic social customs and adaptation. It takes two to three months to complete this program. During this period, they acquire Kore-
} an citizenship and determine where they will live. 
was done to identity socio-demographic characteristics, traumatic experiences, and perceived discrimination on each of 4 factors of national identity. For all independent variables, multicollinearity was small as the value of VIF was lower than 1.5.

\section{RESULTS}

\section{Demographic characteristics}

We presented the result of the descriptive analysis of the variables in Table 1.

\section{Factor loadings of the national identity scale}

In order to confirm the factors of the national identity scale and select for the appropriate questions, we analyzed 29 questions. For the factor analysis, we used the Principal axis factoring method. Using the size of the eigenvalue, cumulative explanatory variance, and Scree plot, we chose the number of factors. Through the Oblimin method, which allows us to determine the association between factors, we rotated the factor structure. If the factor loading was above 0.3 , we interpreted that there is an association between Oblimin method.

According to the results of the factor analysis, there were 7 factors with an eigenvalue higher than 1 , and we chose to extract 4 of the factors, considering the Scree plot, cumulative explanatory variance, and possibility of interpretation.

After extracting those four factors, we performed an oblique rotation and observed the pattern matrix. The results indicated that in the first factor, seven questions had a relatively high factor loading and contained many questions related to feelings associated with a sense of belonging to a country. The factor was named as positive emotion. In the second factor, four questions had high factor loading. The factor was named as negative value. All four questions indicated the negative values of a sense of belonging to a country. In the third factor, six questions had high factor loading and they indicated that par- ticipants were consciousness of belonging to a country. In the fourth factor, six questions showed high factor loading and included many questions concerning positive values of a sense of belonging to a country. The remaining six questions did not show any high factor loading related to any of the factors, so they were removed it from any further analysis. We performed factor analysis on 23 questions previously selected through factor analysis. We excluded the two questions where the relationship between the question and the factor did not correspond to the theoretical structure from the analysis.

Finally, we confirmed our results with the national identity scale, which consisted of 21 questions associated with 4 factors. The pattern matrix for those 21 questions is shown in Table 1. Question 18 and Question 20 showed factor loading higher than 0.4 for two of the factors, so we included them in the factors, which were more theoretically appropriate.

Factor 1 indicates being consciousness about being a South Korean national, so it was named "national consciousness." Factor 2, named "positive emotions", indicates the positive emotions about being a South Korean national. Factor 3 was named "positive value evaluation" and indicates the positive values of being a South Korean national. Factor 4 indicates the negative value of being a South Korean national, so it was named "negative value evaluation" (Table 2).

The interfactor correlation between national consciousness and positive emotions is 0.665 ( $\mathrm{p}<0.001)$. Correlation between national consciousness and positive values is $\mathrm{r}=0.540(\mathrm{p}<$ 0.001 ). Correlation between national consciousness and negative value is $\mathrm{r}=-0.386(\mathrm{p}<0.001)$. The $\mathrm{r}$ value is $\mathrm{r}=0.622(\mathrm{p}<$ 0.001 ) for positive emotions and positive value, $r=-0.487$ for positive emotions and negative value, and $\mathrm{r}=-0.347$ for positive values and negative value.

\section{Averages of major variables}

The mean values of major variables from the 500 respon-

Table 1. Demographic characteristics

\begin{tabular}{|c|c|c|c|c|c|}
\hline \multicolumn{2}{|c|}{ Variable } & Mean & $\mathrm{SD}$ & Frequency & $\%$ \\
\hline \multirow{2}{*}{ Gender } & Male & & & 99 & 19.8 \\
\hline & Female & & & 401 & 80.2 \\
\hline Age & & 36.19 & 8.30 & & \\
\hline \multirow[t]{2}{*}{ Level of Education in North Korea } & Less than middle/high school & & & 377 & 75.4 \\
\hline & More than college & & & 123 & 24.6 \\
\hline \multirow[t]{2}{*}{ Cohabiting family } & Yes & & & 310 & 62.0 \\
\hline & No & & & 190 & 38.0 \\
\hline \multirow[t]{2}{*}{ Religion } & Yes & & & 238 & 47.6 \\
\hline & No & & & 262 & 52.4 \\
\hline \multirow{2}{*}{ Current employment status } & Yes & & & 294 & 58.8 \\
\hline & No & & & 206 & 41.2 \\
\hline
\end{tabular}


Table 2. The pattern matrix of national identity subscales

\begin{tabular}{|c|c|c|c|c|c|c|}
\hline Component & Question & Factor 1 & Factor 2 & Factor 3 & Factor 4 & $h^{2}$ \\
\hline \multirow{6}{*}{$\begin{array}{l}\text { National } \\
\text { consciousness }\end{array}$} & 6. I feel that I am living side by side with South Koreans & 0.694 & 0.100 & 0.007 & 0.063 & 0.595 \\
\hline & 5. I feel a sense of unity with South Koreans & 0.644 & 0.006 & -0.013 & 0.098 & 0.479 \\
\hline & 7. I have national consciousness towards South Korea & 0.559 & 0.142 & 0.103 & 0.074 & 0.513 \\
\hline & 26. I am strongly conscious that I am South Korean & 0.460 & -0.033 & 0.264 & 0.216 & 0.548 \\
\hline & 10. I strongly think that I am South Korean & 0.374 & 0.136 & 0.054 & 0.153 & 0.322 \\
\hline & 25. I feel like I belong to the South Korean culture & 0.336 & 0.005 & 0.298 & 0.013 & 0.290 \\
\hline \multirow[t]{6}{*}{ Positive emotion } & 1. I feel good that I am in South Korea & 0.173 & 0.001 & -0.081 & 0.790 & 0.717 \\
\hline & 4. I feel satisfied that I am a South Korean & 0.156 & 0.052 & -0.117 & 0.742 & 0.644 \\
\hline & 2. I feel proud of South Korean traditions & 0.131 & -0.052 & 0.052 & 0.696 & 0.587 \\
\hline & 16. I like living in South Korea currently & -0.002 & 0.209 & 0.071 & 0.583 & 0.564 \\
\hline & 27. I feel proud that I am a South Korean. & 0.172 & 0.036 & 0.194 & 0.497 & 0.541 \\
\hline & 20. When South Korea does well, I feel happy as if I am doing well & -0.161 & 0.174 & 0.459 & 0.439 & 0.639 \\
\hline \multirow{5}{*}{$\begin{array}{l}\text { Positive value } \\
\text { evaluative }\end{array}$} & 22. I am highly interested in how foreigners think about South Korea & 0.067 & -0.063 & 0.657 & -0.086 & 0.399 \\
\hline & 21. When someone criticizes South Korea, I feel that I am being criticized & 0.192 & -0.005 & 0.630 & 0.046 & 0.563 \\
\hline & 19. I want to work hard to develop South Korea & -0.076 & 0.177 & 0.522 & 0.295 & 0.596 \\
\hline & $\begin{array}{l}\text { 23. The fact that I am a South Korean greatly influences my thoughts and } \\
\text { behavior }\end{array}$ & 0.025 & 0.036 & 0.514 & -0.024 & 0.275 \\
\hline & 18. I think that South Korea must do well in order for me to do well & -0.163 & 0.156 & 0.430 & 0.438 & 0.582 \\
\hline \multirow{6}{*}{$\begin{array}{l}\text { Negative value } \\
\text { evaluation }\end{array}$} & 13. I feel uncomfortable that I must get used to South Korea & -0.019 & 0.722 & -0.033 & 0.005 & 0.502 \\
\hline & 9. I do not like that I am a South Korean citizen & -0.032 & 0.709 & 0.035 & 0.053 & 0.547 \\
\hline & 8. I think that I am a useless person in South Korea & 0.103 & 0.529 & -0.008 & -0.113 & 0.265 \\
\hline & 3. I think that I do not have much to boast about South Korea & 0.006 & 0.460 & -0.011 & 0.107 & 0.272 \\
\hline & Eligenvalue & 8.027 & 1.689 & 1.492 & 1.225 & \\
\hline & Explanatory variance $\%$ & 38.22 & 8.04 & 7.11 & 5.83 & \\
\hline
\end{tabular}

dents are shown in Table 3. The average national awareness was $18.06(\mathrm{SD}=2.46)$. The average social network was 5.51 people $(\mathrm{SD}=5.56)$. The experience of perceived discrimination was 14.42 ( $\mathrm{SD}=5.64)$ on average. In terms of trauma, the average childhood trauma was $1.80(\mathrm{SD}=1.94)$, the average trauma experienced in North Korea was $5.06(\mathrm{SD}=3.18)$, and the average trauma experienced during the escape was $2.94(\mathrm{SD}=2.72)$.

\section{Factors that influence national identity}

Sociodemographic characteristics, traumatic experiences, and perceived discrimination explained $8.1 \%$ of the participants national consciousness variability according to the multiple regression analysis (Table 4).

Influential variables that had a significant impact on national consciousness were traumatic experiences during childhood $(\beta=-0.102, p<0.05)$, social network $(\beta=0.129, p<0.01)$, and perceived discrimination $(\beta=-0.176, \mathrm{p}<0.001)$. Therefore, with less traumatic experience during childhood, more social network, and less perceived discrimination, North Koreans had higher national consciousness.

According to the multiple regression analysis of positive emotions, which is perceived discrimination explains $7.7 \%$ of the variability of positive emotions. The influential variables that have significant impact are education level in North Korea $(\beta=-0.094, p<0.05)$, traumatic experience in North Korea $(\beta=0.144, p<0.01)$, social network $(\beta=0.131, p<0.01)$, and perceived discrimination $(\beta=-0.151, \mathrm{p}<0.001)$. Therefore, the lower the level of education received in North Korea, the higher the number of traumatic experiences in North Korea. Also, the larger the social network and less discrimination perceived to have received in South Korea was associated with higher positive emotions towards South Korea.

The sociodemographic characteristics, traumatic experience, and perceived discrimination explain $4.8 \%$ of the variability in positive values according to the multiple regression analysis of positive values, which is a low-ranking factor for national identity. This showed the lowest explanatory variable of the four factors. The factors that showed a significant influence are traumatic experiences in North Korea $(\beta=0.114$, $\mathrm{p}<0.05)$ and social network $(\beta=0.119, \mathrm{p}<0.01)$. Therefore, more traumatic experiences in North Korea and more social networks in South Korea are associated with higher positive val- 
Table 3. Averages of major variables

\begin{tabular}{|c|c|c|c|c|}
\hline Variable & Item & Questions & Mean & $\mathrm{SD}$ \\
\hline \multirow[t]{4}{*}{ National identity } & National consciousness & 6 & 18.06 & 2.46 \\
\hline & Positive emotions & 6 & 20.11 & 2.55 \\
\hline & Positive value & 5 & 15.50 & 2.23 \\
\hline & Negative value & 4 & 7.30 & 1.75 \\
\hline Social network & Social network & 1 & 5.51 & 5.64 \\
\hline Discrimination & Perceived discrimination & 9 & 14.42 & 5.17 \\
\hline \multirow[t]{3}{*}{ Trauma } & Trauma during childhood & 10 & 1.80 & 1.94 \\
\hline & Trauma in North Korea & 17 & 5.06 & 3.18 \\
\hline & Trauma during escape & 18 & 2.94 & 2.72 \\
\hline
\end{tabular}

Table 4. Factors that influence national identity

\begin{tabular}{|c|c|c|c|c|c|c|}
\hline Factor & Variable & $\begin{array}{c}\text { National } \\
\text { consciousness }\end{array}$ & $\begin{array}{l}\text { Positive } \\
\text { emotion }\end{array}$ & $\begin{array}{c}\text { Positive value } \\
\text { evaluation }\end{array}$ & $\begin{array}{c}\text { Negative value } \\
\text { evaluation }\end{array}$ & VIF \\
\hline \multirow{6}{*}{$\begin{array}{l}\text { Sociodemographic } \\
\text { characteristic }\end{array}$} & Gender $^{\mathrm{a}}$ & 0.029 & 0.059 & -0.019 & -0.018 & 1.046 \\
\hline & Age & 0.046 & 0.050 & 0.037 & $0.133^{* *}$ & 1.108 \\
\hline & Education level in North Korea ${ }^{\mathrm{b}}$ & -0.085 & $-0.094^{*}$ & 0.046 & 0.031 & 1.054 \\
\hline & Cohabiting family ${ }^{c}$ & -0.009 & -0.042 & -0.041 & -0.065 & 1.070 \\
\hline & Religion $^{\mathrm{d}}$ & -0.083 & 0.013 & -0.037 & -0.052 & 1.044 \\
\hline & Current employment status ${ }^{\mathrm{e}}$ & -0.025 & -0.026 & -0.084 & -0.038 & 1.040 \\
\hline Experience of discrimination & Perceived & $-0.176^{* * *}$ & $-0.151^{* * *}$ & -0.065 & $0.262^{* * *}$ & 1.087 \\
\hline Social network & Social network & $0.129^{* *}$ & $0.131^{* *}$ & $0.119^{* *}$ & $-0.134^{* *}$ & 1.024 \\
\hline \multirow{4}{*}{$\begin{array}{l}\text { Traumatic } \\
\text { experience }\end{array}$} & Trauma during childhood & $-0.102^{*}$ & 0.018 & 0.030 & 0.054 & 1.178 \\
\hline & Trauma within North Korea & 0.068 & $0.144^{* *}$ & $0.114^{*}$ & -0.088 & 1.452 \\
\hline & Trauma during escape & 0.093 & 0.047 & 0.014 & -0.084 & 1.308 \\
\hline & R-square & $0.081^{* * *}$ & $0.077^{* * *}$ & $0.048^{*}$ & $0.109^{* * *}$ & \\
\hline
\end{tabular}

The values in the table are standardized regression coefficients. ${ }^{a}$ male $=0$, female $=1$, beducation level less than middle/high school $=0$, more than college $=1$, ${ }^{c}$ no family $=0$, with family $=1$, ${ }^{\mathrm{d}}$ no religion $=0$, has religion $=1,{ }^{\mathrm{e}}$ unemployed $=0$, employed $=1 .{ }^{*} \mathrm{p}<0.05,{ }^{* *} \mathrm{p}<0.01,{ }^{* * *} \mathrm{p}<0.001$. VIF: variance inflation factor

ues of South Korea.

According to the multiple regression analysis of negative values, which is a low-ranking factor influencing national identity, the sociodemographic characteristics, traumatic experience, and perceived discrimination explained $10.9 \%$ of the national identity variability. This shows the highest explanatory variability among the four factors. The factors that showed significant influence are age $(\beta=0.133, \mathrm{p}<0.01)$, social network $(\beta=-0.134, p<0.01)$, and perceived discrimination $(\beta=0.262, p<0.001)$. Therefore, older age, less social network, and more discrimination perceived are associated with negative values of South Korea.

\section{DISCUSSION}

According to the results, socio-economic factors do not affect North Koreans in building their national identity regarding resettlement in South Korea.
Gender differences, along with living with family, religion, and employment status, did not contribute to the national identity of 4 factors. This result stands out considering that men spend more than seven years in military service. Those with older age have higher negative value judgment, and those with lower education level from North Korea reported to have stronger positive attitude. The negative attitude from older North Koreans can be interpreted as those who are elderly did not defect voluntarily but rather unwillingly due to their family member's defection. Also, the older generation of North Koreans may have developed positive perception towards communist regime because they experienced North Korea before the Great Depression, which in turn may have contributed to negative attitude towards resettlement in South Korea. The lower education level from North Korea could be construed in many different ways. The main causes could be that the lack of education creates a barrier to better education, employment, and better social economic status in North Korea. Therefore, 
those with lower educational status have a positive attitude towards becoming a South Korean citizen because of the prospect of living a better life.

Discriminatory experiences in South Korea substantially influenced their sense of belonging in South Korea. The actual discriminatory experience in South Korea was relatively low. The overall average was 14.42 (5.17), which is interpreted as rarely or sometimes experiencing discrimination. Relatively higher discriminatory experience was described as "treated differently for being a North Korean" (2.13). Relatively lower discriminatory experience was "threat or harassment" (1.26). This result agrees with the results of a study done by Yoon. ${ }^{34}$ The difference of the results may come from the study subjects since they defected from North Korea in 2007 and have lived in South Korea for one year, which may be the "honeymoon period" of resettlement for refugees. The "honeymoon period" can be described as the period when the government and resettlement agencies support their resettlement and thus the refugees have not gone out in the employment market to experience social discrimination. Such phenomena could be further researched through follow up studies. However, relatively small discriminatory experience has also negatively affected North Koreans in re-establishing their national identity. The present study has shown that even the infrequent discriminatory experiences can lead to a disturbance in establishing one's national identity. This indicates that the South Korean government and society have to provide North Korean refugees with more support in establishing a sense of belonging and national identity as South Koreans. The South Korean society has to set out social policies for North Korean refugees as well as South Koreans to embrace North Korean refugees.

The social network results showed that the lower four scales showed statistical significance. Having more social networks, formed stronger positive national identity among North Korean refugees. Therefore, supporting North Koreans by helping them to establish more social networks is as important as providing economic and social support. Currently, the South Korean government runs Hanawon, which is a resettlement center that gives North Koreans support for their first two months of resettlement. However, there needs to be a social support through religious institutions such as church, chapel, local NGO, school, and local community for North Korean refugees to establish South Korean national identity and positive social network.

Previous research has shown that trauma during early childhood inhibits one in establishing a sense of belonging in a certain community. ${ }^{35,36}$ North Korean refugees who reported experiencing childhood trauma established weaker national identity as South Koreans. It can be interpreted that those who experienced trauma at an early age in North Korea were not been protected by family and society, which hinders them from feeling a sense of belonging in a certain community. However, those who experienced trauma in their adulthood showed a positive response in establishing their national identity as South Koreans. This means that experiencing trauma as adults has imprinted a negative image and emotions toward North Korea, which acts positively in establishing national identity as South Korean during resettlement. However, trauma that occurs during the transition stage while residing in China before coming to South Korea did not affect any of the participants in establishing their national identity as South Korean. This could be interpreted as North Korean refugees considering trauma in the third world as experience unrelated to either North Korea or South Korea. North Koreans who experienced trauma were more sensitive and vulnerable. Therefore, if North Korean refugees experienced discrimination in South Korea, they may have more difficulties with resettlement. Therefore, more support and help may be needed to help them resettle.

\section{Limitations}

The study subjects have resettled in South Korea, however, they have not spent enough time in South Korea to explain the overall situation of resettlement and the changes in terms of national identity over the coming years. It is a bit presumptuous to generalize the national identity of North Korean refugees who have resided for a long period and those who did not participate in the study. However, this study is valuable in that it serves as a foundation to assess national identity of North Korean refugees according to their respective durations of settlement.

\section{Acknowledgments}

This work was supported by the Korea Research Foundation Grant funded by the Korean Government (KRF- 2008-321-B00120).

\section{REFERENCES}

1. Ministry of Unification. 2010 White Paper on Unification. Seoul: Ministry of Unification; 2011.

2. Yoon IJ. Social adjustments of North Korean migrants and measures to facilitate their resettlement. J Asiat Studies 2007;50:106-182.

3. Brubaker R. Citizenship and Nationhood in France and Germany. Cambridge, MA: Harvard University Press; 1992.

4. De Figueiredo, Rui JP, Elkins Z. Are patriots bigots? An inquiry into the vices of in-group pride. Am J Polit Sci 2003;47:171-188.

5. Hjerm M. National identities, national pride, and xenophobia: a comparison of four western countries. Acta Sociol 1998;41:335-347.

6. Smith TW, Kim SH. National pride in cross-national and temporal perspective. Int J Public Opin Res 2006;18:127-136.

7. Chae JM. The Mechanisms and Patterns of the North Korean Refugees Psychological Acculturation in the Republic of Korea. Seoul: Graduate School of Korea University; 2003.

8. Lee HJ. The Abuses of Human Rights and Identity Change Processes 
of Women Refugees from North Korea - Focusing on Married Lives of North Korean Women Refugees in North Korea, China, and South Korea. Seoul: Hanyang University; 2003.

9. Ellis BH, MacDonald HZ, Klunk-Gillis J, Lincoln A, Strunin L, Cabral HJ. Discrimination and mental health among Somali refugee adolescents: the role of acculturation and gender. Am J Orthopsychiatry 2010; 80:564-575.

10. Phinney JS. Ethnic identity in adolescents and adults: review of research. Psychol Bull 1990;108:499-514.

11. Yoon IJ. North Korean refugees and their social adjustment: the case for refugees in South Korea. N Korean Stud Rev 2001;3:123-184.

12. Shim WY. Racial identity and psychological attitudes of multicultural students. J Elementary Edu 2009;22;27-47.

13. Emirbayer M, Goodwin J. Network analysis, culture, and the problem of agency. AM J Sociol 1994;99:1411-1454.

14. Somers MR. The narrative constitution of identity: a relational and network approach. Theory Soc 1994;23:605-649.

15. Baiely T, Waldinger R. Primary, secondary, and enclave labor markets: a training systems approach. Am Sociol Rev 1991;56:432-445.

16. Baron RS, Cutrona CE, Hicklin D, Russell DW, Lubaroff DM. Social support and immune function among spouses of cancer patients. J Pers Soc Psychol 1990;59:344-352.

17. Cassel J. The contribution of the social environment to host resistance: the Fourth Wade Hampton Frost Lecture. Am J Epidemiol 1976;104: 107-123.

18. Pressman SD, Cohen S, Miller GE, Barkin A, Rabin BS, Treanor JJ. Loneliness, social network size, and immune response to influenza vaccination in college freshmen. Health Psychol 2005;24:297-306.

19. Park JH, Chung JY. Acculturation and identity of immigrant wives of international marriages in Korea. Korean J Woman 2007;12;395-432.

20. Kim MR. The effect of the perceived adjustment stress and the coping resources on the depressive symptoms of the North Korean refugees: the comparison between men and women. Ment Health Soc Work 2005; 20:95-124.

21. Keyes EF, Kane CF. Belonging and adapting: mental health of Bosnian refugees living in the United States. Issues Ment Health Nurs 2004;25: 809-831.

22. Fantino AM, Colak A. Refugee children in Canada: searching for identity. Child Welfare 2001;80:587-596.

23. Seong HG. Development of Korean social identification scale. Korean J Soc Pers Psychol 2001;15:33-48.

24. Tajfel H. Social Categorization, Social Identity and Social Comparison. In: Tajfel H, Editor. Differentiation between Social Groups: Studies in the Social Psychology of Intergroup Relations. London: Academic Press; 1978, p.336-337.

25. Keum MJ, Kwon HS, Lee HW. The acculturation process of North Korean adolescents refugees. Korean J Couns Psychother 2004;16:295-308.

26. Chung JK. Korean sense of community scale. KJPSI 1999;5:19-30.

27. Kim HS. Korea Aggregation Self-esteem Scale, Korean Psychological Association 1993 Annual competition Thesis Collection of conference proceedings. 1993.

28. Essed P. Understanding Everyday Racism: An Interdisciplinary Theory. Thousand Oaks, CA: Sage; 1991.

29. Wellman B, Gulia M. Net-surfers Don't Ride Alone: Virtual Communities as Communities. In: Wellman B, Editor. Networks in the Global Village. Life in Contemporary Communities. Oxford: West View Press, 1999, p.2-27.

30. Wellman B. Physical place and cyberplace: the rise of personalized networking. Int J Urban Reg Res 2001;25:227-252.

31. Youm YS. The Variety of Settlement Level and Social Network of North Korean Refugees. Seoul: North Korean Refugees Foundation; 2010.

32. Kessler RC, Magee WJ. Childhood family violence and adult recurrent depression. J Health Soc Behav 1994;35:13-27.

33. Kang SR. Development of Trauma Scale for North Korean Refugee. Seoul: Yonsei University; 2001.

34. Yoon IJ, Gil EB, Park YH, Eoum HS, Yoon YS, Chae JM. The Research on the Actual Condition of North Korean Refugees Woman, Youth. Database Center for North Korean Human Rights; 2006.

35. Goodwin RD, Stein MB. Association between childhood trauma and physical disorders among adults in the United States. Psychol Med 2004; 34:509-520.

36. Kia-Keating M, Ellis BH. Belonging and connection to school in resettlement: young refugees, school belonging, and psychosocial adjustment. Clin Child Psychol Psychiatry 2007;12:29-43. 